\title{
Effects of aging on interjoint coordination during arm reaching
}

\author{
Marcus Vinicius da Silva, Leia Bernardi Bagesteiro*
}

\begin{abstract}
Introduction: Moving the arm towards an object is a complex task. Movements of the arm joints must be well coordinated in order to obtain a smooth and accurate hand trajectory. Most studies regarding reaching movements address young subjects. Coordination differences in the neural mechanism underlying motor control throughout the life stages is yet unknown. The understanding of these changes can lead to a better comprehension of neuromotor pathologies and therefore to more suitable therapies. Methods: Our purpose was to investigate interjoint coordination in three different aging groups (children, young, elderly). Kinematics and kinetics specific variables were analyzed focusing on defined parameters to get insight into arm coordination. Intersegmental dynamics was used to calculate shoulder and elbow torques assuming a 2-link segment model of the upper extremity (upper arm and forearm) with two friction-less joints (shoulder and elbow). A virtual reality environment was used to examine multidirectional planar reaching in three different directions (randomly presented). Results: Seven measures were computed to investigate group interlimb differences: shoulder and elbow muscle torques (peak and impulse), work performed by shoulder and elbow joints, maximum velocity, movement distance, distance error at final position, movement duration and acceleration duration. Our data analysis showed differences between movement performances for all analyzed variables, at all ages. Conclusion: We found that the intersegmental dynamics for the interlimb (left/right) comparisons were similar for the elderly and children groups as compared to the young. In addition, the coordination and control of motor tasks changes during life, becoming less effective in old age.
\end{abstract}

Keywords: Arm reaching, Kinetics, Motor coordination, Aging.

\section{Introduction}

The ability to move the arm is essential for almost all daily living activities, such as personal hygiene, eating and dressing. These movements can be defined as the voluntary positioning of the hand in a desired location in space, so that there is interaction with the environment, which requires the coordination of multiple joints of the arm and involves the musculoskeletal and nervous systems. Reaching movements are generated through motor commands from the brain to predict the dynamic forces of a desired trajectory and, with practice; these commands are modified, increasing the efficiency of the movement (Shadmehr and Moussavi, 2000). To produce the desired trajectory, forces in the muscles must be coordinated with the external forces imposed by the environment, as well as additional forces arising within the musculoskeletal system. Internal forces include interactions imposed by the movement of the different segments of the arm and the forces that results from the expansion and contraction of non-contractile tissue. External forces include, for instance, the gravity and contact forces.

Studies indicate that each hemisphere of the brain became specialized for different processes, however, complementary in control of the processes responsible for the movements, this phenomenon probably occurred in order to reduce the execution time and energy expenditure associated with the transmission of information to the neural networks, thus each hemisphere contributes in a unique way in the control of a given task (Mutha et al., 2013; Tutkuviene and Schiefenhövel, 2013).

Other studies combining analysis of the trajectory of the hand, inter-joints coordination, electromyography and inverse dynamics have shown that several variables, kinetic and kinematics, can be used to infer the different strategies associated with reaching movements. Also these parameters can differ, when analyzing, for example, the dominant arm (right, in case of right-handed people, and left, in case of left-handed people) or the non-dominant arm. (Bagesteiro and Sainburg, 2002; Sainburg, 2002; Sainburg and Kalakanis, 2000; Sainburg and Schaefer, 2004).

A relevant study (Gooderham and Bryden, 2014) followed children from 8 weeks to 10 years of age, where it was reported that children up to 3 years had mixed control of the upper limbs and that with the increase of the age, the child was developing a 
preference for a particular arm. This property has been reported in several studies showing that, in children, the control of the parameters of the reaching movement is achieved in different stages (proportions) of development: for instance, the hand trajectory is "softer" and less variable with age, and inter-joint coordination becomes more consistent (Favilla, 2006; Ferrel-Chapus et al., 2002; Lambert and Bard, 2005; Rival et al., 2003; Schneiberg et al., 2002; Wilson and Hyde, 2013).

Likewise, studies in elderly using a variety of motor tasks established that many aspects of motor control are affected by aging, causing slower movement and less coordinated (Danion et al., 2007; Heuninckx et al., 2004; Holtrop et al., 2014; Lee et al., 2007; Linortner et al., 2014; Yan, 2000). It is known that, with advancing of the age, a decline in the control and functioning of sensorimotor system emerges, which implies that elderly people often face great difficulties in interacting with the environment and perform simple daily tasks, thereby reducing their freedom and independence (Seidler et al., 2010).

These findings appear to imply on fundamental differences in the strategies of motor control in children, young and elderly. In fact, in a study of human arm movements (Yan, 2000), elderly shows motor programming and execution deficits when compare to young adults and older children. Therefore, there would be improvement of movement quality and control in the first years of life, reaching its apex in youth and becoming deteriorated in old age, this may be due to a reduction in hemispheric asymmetry for cognitive tasks, although further studies are necessary before anything can be stated with certainty (Przybyla et al., 2011). Nevertheless, young and older show different strategies to perform reaching movements. While the young group relies completely on visual information to execute the proposed task, the older group presented a greater reliance on feedback mechanisms (Bagesteiro, 2013).

An attempt to compare different levels of movement coordination and energetic efficiency during life is to estimate power values of a movement performed by representative subjects of each phase of the life (children, young and elderly). This analysis can help to identify different motor control strategies between such groups, since this quantity is directly related to the torque generated during the task. Apparently, in the energetic point of view, human beings tend to perform movements as economic as possible, i.e., the muscles do not perform more mechanical work than necessary to conclude certain motor tasks, thus having a lower metabolic cost (Zelik and Kuo,
2012). As the power is associated with the movement efficiency (Arampatzis et al., 2000; Schepens et al., 2001; Zelik and Kuo, 2012; Winter, 1983), it is possible to determine whether there is deterioration in the quality of the movement after the young stage of the subject. The analysis of these differences may provide relevant information that will help to improve the understanding of the changes in the motor system with advancing age.

In the present study, we applied inverse dynamics analysis to evaluate the torque and work performed by the arm (shoulder and elbow joints) generated during the reaching movement of subjects belonging to the three groups (elderly, young and children), in order to investigate changes in motor control related to development and aging. Movements were made to three different visual targets, with different joint excursion requirements. Thus, it was possible to examine how subjects from different age groups coordinated multidirectional reaching movements in the horizontal plane. In order to analyze movement coordination specific features of the movements were selected, both kinetic and kinematic.

It is expected that these analyzes assist the creation of new methods for examination of differences related to the development of mechanisms of control and motor coordination, which are essential when desiging specific techniques of physical activities directed to particular populations, as well as for patients' rehabilitation.

\section{Methods}

\section{Participants}

Thirty-six participants were divided into three groups: children, young and elders. Subjects had no historical neurological problems and/or musculoskeletal diseases.

Subjects were all right-handed, based on the score obtained from a modified version of a thirty-four items of the Edinburgh Inventory (Oldfield, 1971), on this test several routine activities are proposed to the participants and, depending on their performance, a value is assigned, thereby, the handedness of a person can be quantitatively determined right-handed (dominant) or left-handed (non-dominant).

Participants were unaware of the purpose of the study, and received a brief description of the task. The study was approved by ethics committee (CEP/ UNIFESP/HSP, CEP/UNICID/0006.0.186.000-06) and all volunteers gave informed consent prior to participation. Table 1 summarizes the characteristics of each group. 


\section{Experimental setup}

The experimental setup applied in this study was identical to some previous studies (Bagesteiro, 2013; Bagesteiro and Silva, 2011; Bagesteiro and Sainburg, 2002). Four magnetic 6-DOF motion sensors (Flock of birds, Ascension Technology, Shelburne, VT, USA) recording position and orientation of each arm segment were used to monitor the limb movement. Figure 1 illustrates the experiment setup.

Sensors digital data was collected at $103 \mathrm{~Hz}$ using a Macintosh computer through separated serial ports using custom software written in REAL BASIC TM (REAL Software, Inc.) and IgorPro TM (Wavemetrics, Inc.). Data was stored on disk for further processing and analysis.

\section{Experimental task}

Three targets were presented: "target 0" (T45) oriented $45^{\circ}$ relative to the horizontal axis (i.e. requiring mostly elbow joint movements), "target 1 " (T90) oriented $90^{\circ}$ (requiring shoulder and elbow joints movements), and "target 2" (T135) oriented at $135^{\circ}$ (requiring greater shoulder joint movement).

Before the start of each trial the cursor and start circle were displayed on the screen. To begin the trial the subject was required to hold the cursor within the

Table 1. Summary of participants' information

\begin{tabular}{lccc}
\hline $\begin{array}{c}\text { Variable } \\
(\text { Mean } \pm \text { SD) }\end{array}$ & Children & Young & Elder \\
\hline Number $(\mathrm{N})$ & 12 & 12 & 12 \\
Age (year) & $9 \pm 1$ & $22 \pm 3$ & $71 \pm 4$ \\
Weight $(\mathrm{kg})$ & $33.7 \pm 7.6$ & $71.9 \pm 13.1$ & $69.8 \pm 13.3$ \\
Height $(\mathrm{m})$ & $1.30 \pm 0.10$ & $1.70 \pm 0.10$ & $1.60 \pm 0.10$ \\
\hline
\end{tabular}

starting circle and after a 300ms delay an audio-visual "go" signal and one of the three targets was displayed. Participants were instructed to move the finger to the target using a single, uncorrected, rapid motion.

Each subject was given a practice session (40 trials) to familiarize themselves with the task, followed by the real experimental task, where 90 (in case of young and elder) or 72 (in case of children) trials for each arm were performed, totaling 180 trials for the young and elder groups and 144 trials for the children. The linear distance between the targets and the starting position was $15-\mathrm{cm}$ for young and elder and $12-\mathrm{cm}$ for the children. Figure 2 shows the positions of the targets.

\section{Kinematic data analysis}

Elbow and shoulder positions and angles were calculated from sensors position and orientation data. All kinematic data were low-pass filtered at $8 \mathrm{~Hz}$ using a 3rd order, no lag, dual pass Butterworth filter and differentiated to yield angular velocity and acceleration values.

Movement onset was determined by the last minimum (below 5\% maximum tangential velocity) prior to the maximum in the index finger's tangential velocity profile. Movement termination was defined as the first minimum (below 5\% maximum tangential hand velocity) following the peak in tangential hand velocity.

With time and position data provided by the sensors fixed on the arm segments it was possible to determine the distance of the trajectory of the hand, and the value of maximum velocity and acceleration of the movement (obtained by differentiating the displacement data). Final position error was calculated
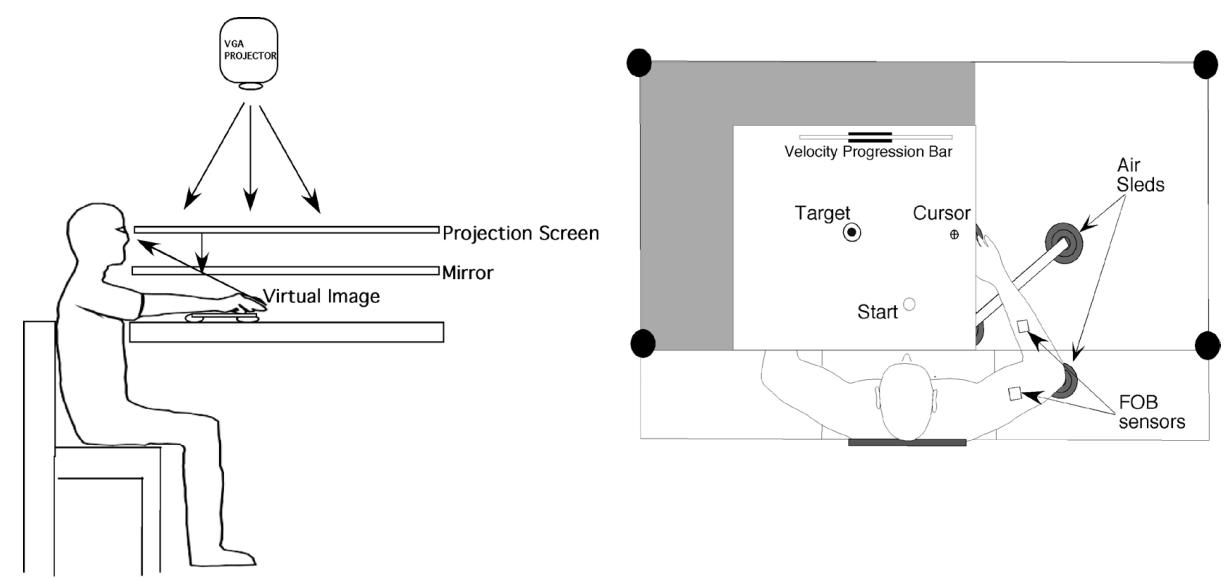

Figure 1. Experimental apparatus (lateral and top view). 


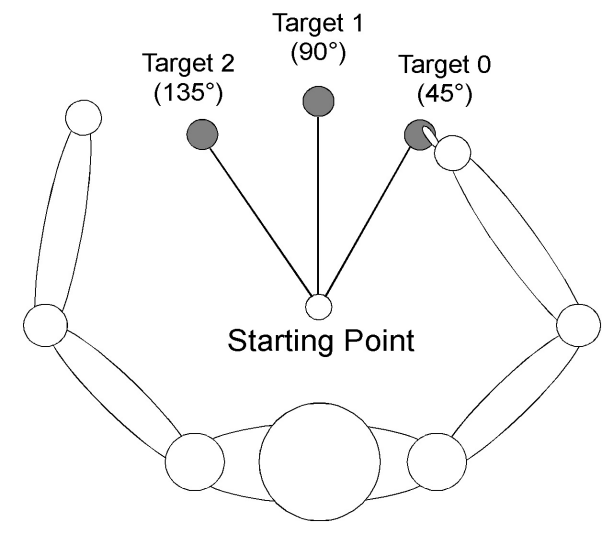

Figure 2. Target position throughout the experimental task.

as the distance between the index finger location at movement end and the center of the target location. Movement duration was defined as the elapsed time from movement start to movement end. The joint contributions to the initial acceleration phase of motion were quantified as the ratio of shoulder excursion to elbow excursion, measured at peak tangential hand velocity, thus it was possible to determine the differences between the movements to each target (T45, T90 and T135).

\section{Kinetic data analysis}

We used a planar 2-segment rigid body model to calculate the joint torques at the shoulder and elbow. In order to understand the kinetic basis the terms of the equations of motion at each joint were partitioned into three main components: interaction torque, muscle torque, and net torque (Bagesteiro and Sainburg, 2002; Bagesteiro and Silva, 2011). Interaction torque represents the rotational effect of the forces caused by the rotation and linear motion of the other segment. Muscle torque mainly represents the rotational effect of muscle forces acting on the segment. Nevertheless, muscle joint torque also includes the passive effects of soft tissue deformation and does not distinguish muscle forces that counter one another during co-contraction. Net torque is directly proportional to the joint acceleration and is expressed by the sum of muscle and interaction torques.

The torques were computed and analyzed for both joints (shoulder and elbow) as detailed in (Bagesteiro and Sainburg, 2002 and Bagesteiro and Silva, 2011). Body weight and limb segments lengths were used to calculate limb segment inertia, center of mass location and mass (Winter, 2004).
As the distance between the movement start point and the target were different for the children group, all kinetic variables were normalized by multiplying the linear distance of movement (calculated for each trial) by the torque value, and dividing by the standard distance ( $15 \mathrm{~cm}$ in the case of older and younger, and $12 \mathrm{~cm}$ in the case of children).

Shoulder and elbow joint power was calculated as the product of angular velocity and muscle torque. We also calculated the integral of muscle torque and joint velocity, i.e. joint work at the elbow and shoulder (for equations see Enoka, 2002). For each trial, muscle torque and joint angular velocity values were analyzed separately into positive (acceleration phase) and negative (deceleration phase) portions, in order to check the differences in energy absorption and generation of each movement. In addition, we were interested in the differences of joint power across directions and its relation with movement phases.

\section{Statistical analysis}

We examined the means of our kinematic and kinetic dependent measures using repeated-measures analysis of variance (ANOVA) (3 (Age) x 3 (Target) $\mathrm{x} 2$ (Hand)) with one between-subject factor (Age: Children, Young, and Elder) and two within-subject factors (Target direction: $45^{\circ}, 90^{\circ}$ and $135^{\circ}$; and Hand: Right (D) and Left (ND)). Subjects were treated as a random factor and for all analysis, statistical significance was tested using an alpha value of 0.05 and Tukey honestly significantly different (HSD) post hoc analyze.

\section{Results}

\section{Hand kinematics}

Interestingly, both hands of each individual group moved at similar velocities for the different targets. Therefore we only illustrate typical velocity profiles for the right (dominant) arm of a representative participant from each group in Figure 3. It is apparent that the young group (mean $\pm \mathrm{SD}$ ) $(\mathrm{T} 45: 1.38 \pm 0.25 \mathrm{~m} / \mathrm{s}$; T90: $1.08 \pm 0.19 \mathrm{~m} / \mathrm{s}$ and T135: $0.85 \pm 0.13 \mathrm{~m} / \mathrm{s})$ moved faster than the elderly (T45: $0.79 \pm 0.30 \mathrm{~m} / \mathrm{s}$; T90: $0.62 \pm 0.21 \mathrm{~m} / \mathrm{s}$ and T135: $0.51 \pm 0.16 \mathrm{~m} / \mathrm{s})$ and children (T45: $0.61 \pm 0.14 \mathrm{~m} / \mathrm{s} ;$ T90: $0.54 \pm 0.13 \mathrm{~m} / \mathrm{s}$ and T135: $0.42 \pm 0.08 \mathrm{~m} / \mathrm{s}$ ). There was a main effect of group $[\mathrm{P}<0.0001]$ and a group $v s$. target interaction $[\mathrm{P}<0.0001]$. Trajectory deviation showed similar effects (Group: $\mathrm{P}<0.0001$; Group vs. Target: $\mathrm{P}<0.0001$ ). Typical handpaths of a representative participant for the right (dominant) am from each group are shown in Figure 3 insets. Trajectory of the young group seems to be more directly to the target as compared to the elder and children group, which seems to be 

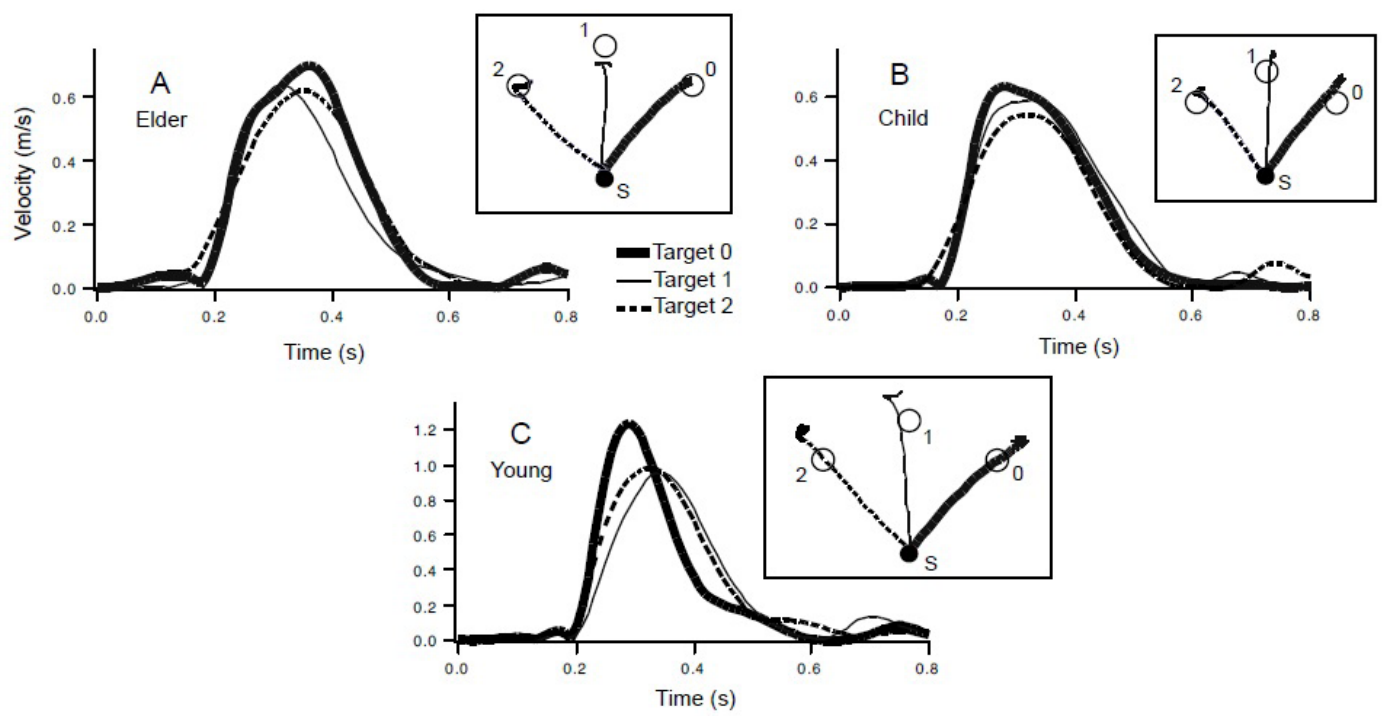

Figure 3. Tangential velocity profiles for representative subjects from each age group ( $A=E l d e r, B=C h i l d$ and $C=$ Young). (Insets) Hand path trajectories for movements toward the three different targets, 'S': start location (displayed at the same coordinate system).

initially directed laterally, hooking back toward the target at the end of motion.

The consistency of these differences, across all groups, is shown in Figure 4A and 4B, which compares measures of peak tangential hand velocity (Figure 4A) and trajectory deviation from linearity (Figure 4B). The greater velocity of the young (Y: $1.10 \pm 0.29 \mathrm{~m} / \mathrm{s}$; E: $0.64 \pm 0.26 \mathrm{~m} / \mathrm{s} ; \mathrm{K}: 0.52 \pm 0.14 \mathrm{~m} / \mathrm{s}$ ) group reflects in a reduction of the accuracy, once this group shows a significative greater error at final position $[\mathrm{P}=0.0053 ; \mathrm{Y}: 0.012 \pm 0.019 \mathrm{~m} ; \mathrm{E}: 0.005 \pm 0.022 \mathrm{~m}$; $\mathrm{K}: 0.003 \pm 0.021 \mathrm{~m}]$, due to this effect the movement distance on this group is also significantly higher than the other groups $[\mathrm{P}<0.0001 ; \mathrm{Y}: 0.17 \pm 0.02 \mathrm{~m}$; E: $0.15 \pm 0.02 \mathrm{~m} ; \mathrm{K}: 0.12 \pm 0.02 \mathrm{~m}]$. There was also a significant group and hand interaction for movement distance $[\mathrm{P}=0.0037]$ and error $[\mathrm{P}=0.0002]$, showing that the elder and children groups had the worse error with their right (D) hand as compared with the left (ND) hand, therefore moving longer with those hands. Young adults presented interlimb differences, with greater errors and longer distances as compared to the other two groups. These effects are shown in Figure $4 \mathrm{C}$ and $4 \mathrm{D}$.

Figure $4 \mathrm{E}$ and $4 \mathrm{~F}$ show means $( \pm \mathrm{SE})$ movement duration (4E) and acceleration duration (4F) across subjects for each target in each group. Consistent with these plots, our ANOVA revealed that there was a significant main effect of group [P=0.0005], with longer times for the elder group $(0.65 \pm 0.19 \mathrm{~s})$ relative to children $(0.61 \pm 0.12 \mathrm{~s})$ and the young group $(0.44 \pm 0.11 \mathrm{~s})$. There was also a significant interaction between group and hand $[\mathrm{P}=0.0164]$, such that the duration of movements for the left (ND) hand of children and elder subjects were significantly longer than the right (D) hand, whereas the young group showed similar duration for both hands. In addition, acceleration duration showed a significant main effect for group [P $=0.0052]$, indicating that the young group $(0.15 \pm 0.05 \mathrm{~s})$ spent less time in the acceleration phase of the moveent as compared with elderly $(0.24 \pm 0.09 \mathrm{~s})$ and children $(0.23 \pm 0.08 \mathrm{~s})$. There was also a significant interaction between hand and group [ $\mathrm{P}=0.0037]$, indicating that the left (ND) arm of the children $(0.25 \pm 0.08 \mathrm{~s})$ and elderly $(0.26 \pm 0.10 \mathrm{~s})$ groups had the longest acceleration phase compared to the right (D) arms (K: $0.21 \pm 0.07 \mathrm{~s}$; E: $0.23 \pm 0.08 \mathrm{~s})$, whereas the young group showed similar phases for both hands $(0.15 \pm 0.05 \mathrm{~s})$.

\section{Hand kinetics}

Representative joint torque profiles for each age group are presented in Figure 5. Elbow and shoulder muscle torque profiles are shown from movement initiation to $350 \mathrm{~ms}$ following movement initiation. Positive values indicate flexor torque; negative values indicate extensor torque. Paying attention to the first $150 \mathrm{~ms}$ of the movement the pattern of the torque profiles was comparable to all groups. At the elbow joint (dashed lines), muscle torque showed decreasing extensor phases as target direction moved towards the medial line (increasing the amount of shoulder motion), whereas shoulder muscle torque (solid lines) started with an extensor phase and gradually changed 

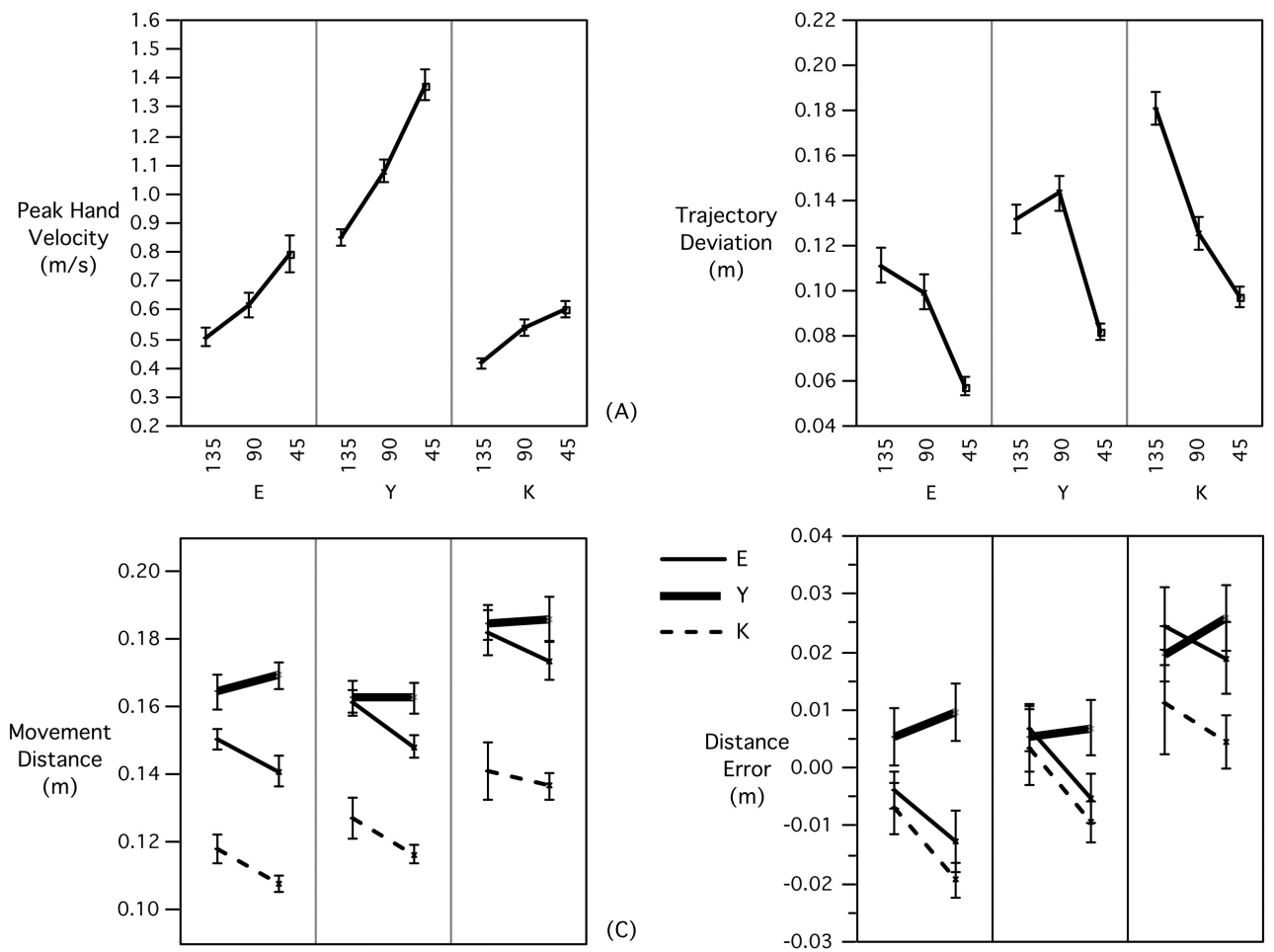

(D)
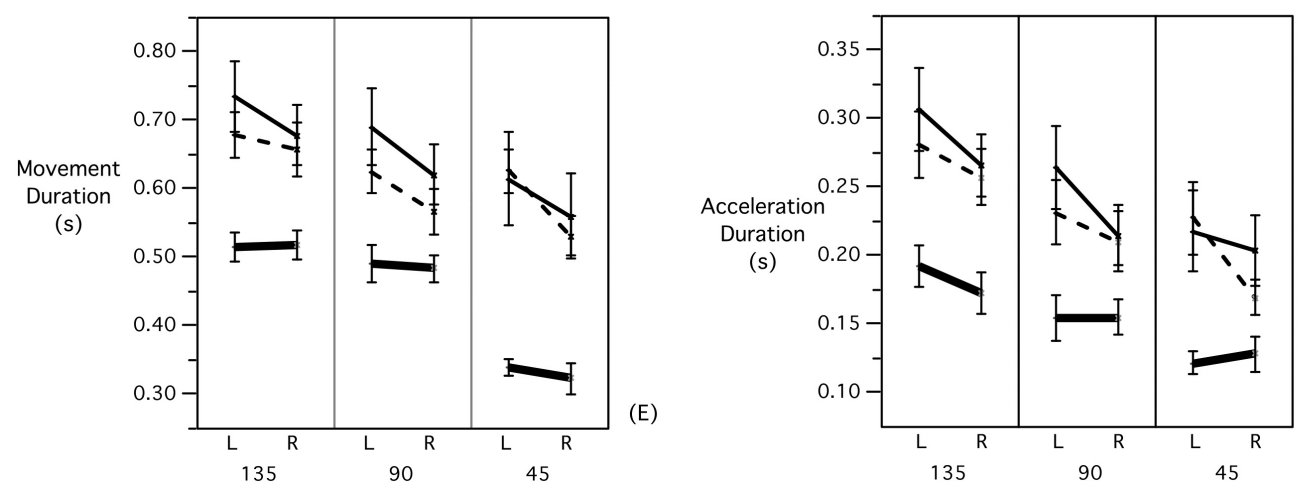

(F)

Figure 4. Kinematic comparisons between groups (E: Elder, K: Children, Y: Young), targets (45, 90, and 135) and hands (right (R) and left (L)). (A): Peak Tangential Hand velocity; (B): Trajectory Deviation from linearity; (C): Movement Distance; (D): Distance Error from the Target; (E): Movement Duration; (F): Acceleration Phase Duration.

to a flexor phase. We quantified the initial peak joint muscle torque across groups. Elderly and children showed no significant differences between left (ND) and right (D) arms, whereas the young group presented significantly higher values for the right (D) arm. Our ANOVA revealed a significant main effect of group on initial peak shoulder $[\mathrm{P}=0.0453]$ and elbow $[\mathrm{P}<0.0001]$ muscle torques (see Figure 6A and 6B). At the elbow joint the young group showed greater peak flexor muscle torque $(3.75 \pm 2.47 \mathrm{Nm})$ as compared to the elderly $(1.85 \pm 1.51 \mathrm{Nm})$ and children $(1.04 \pm 0.69 \mathrm{Nm})$. Also, there was an interaction between hand and group for peak elbow muscle torque [P $=0.0421]$ showing that peak torques for the left (ND) arm of the young group $(4.03 \pm 2.45 \mathrm{Nm})$ are significantly higher than the right (D) arm $(3.48 \pm 2.46 \mathrm{Nm})$ while the elderly and children groups had no significant interlimb differences. As expected, at the shoulder joint, the young group produced greater muscle torques and there was a group $v s$. hand interaction $[\mathrm{P}=0.0009]$ showing that peak torques for the right (D) arm $(2.72 \pm 2.38 \mathrm{Nm})$ are significantly higher than the left $(\mathrm{ND}) \operatorname{arm}(1.63 \pm 1.51 \mathrm{Nm})$ whereas the elderly and children groups presented no significant interlimb differences.

These findings were confirmed with the measures of joint muscle torque impulse (average $\pm \mathrm{SE}$ ), calculated over the acceleration duration as shown 

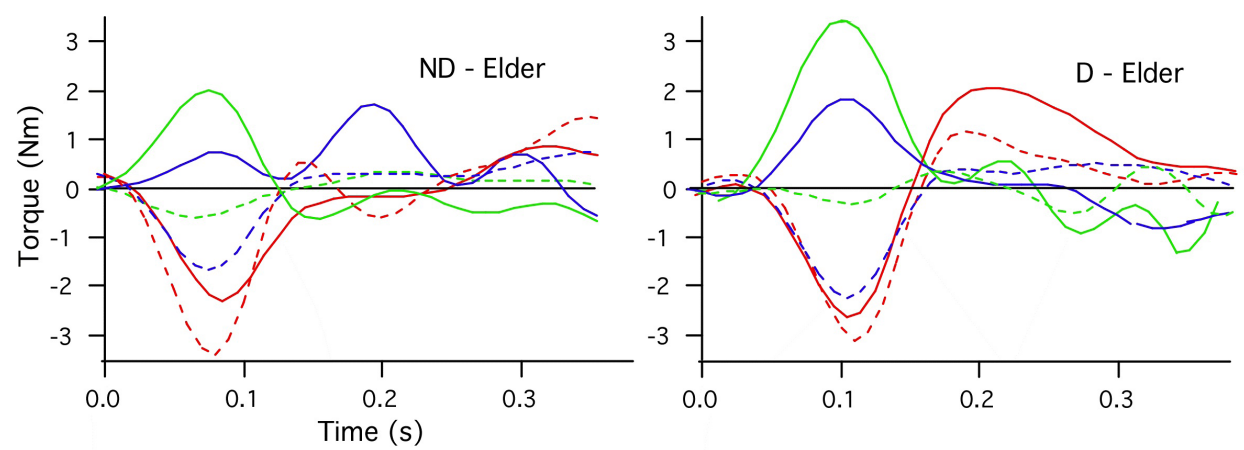

(A)
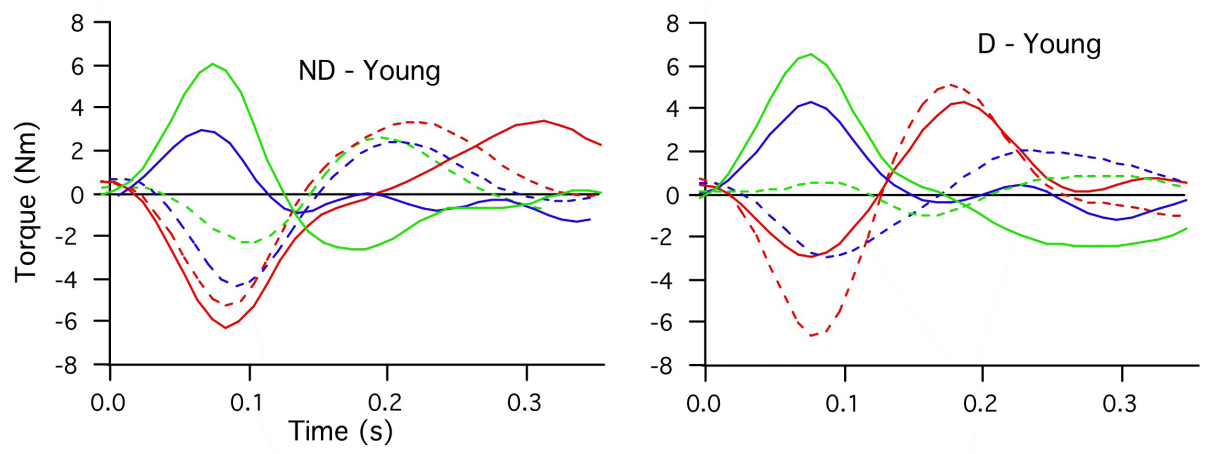

(B)
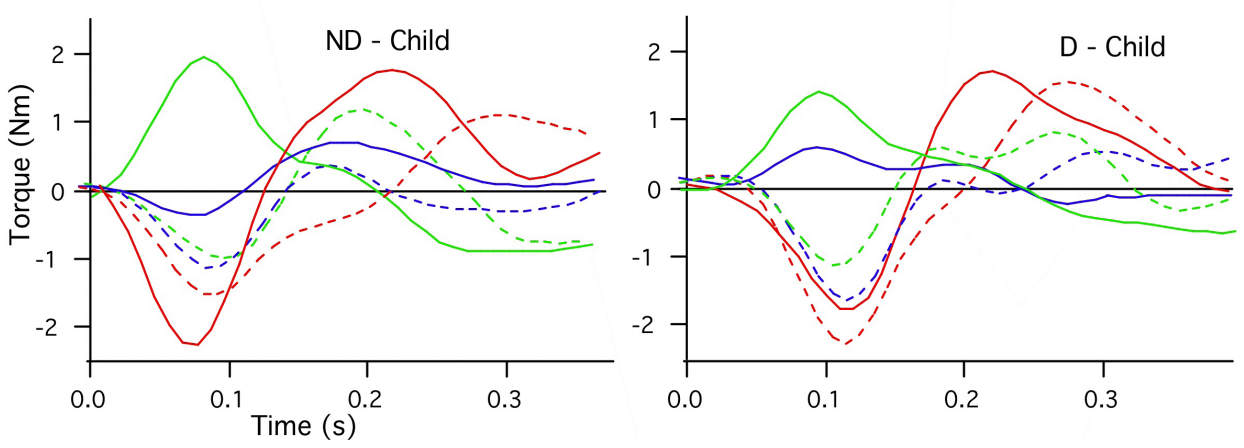

(C)

Figure 5. Muscle torque profiles for a representative subject from each group: (A) Elder, (B) Young, (C) Child; ND = left (L), D = right (R); $\mathrm{T} 45=$ red, $\mathrm{T} 90=$ blue, $\mathrm{T} 135=$ green; Shoulder $=$ solid line, Elbow $=$ dashed line.

in Figure 6C (elbow) and 6D (shoulder). There was a significant difference between groups for elbow $[\mathrm{P}<0.0001]$ and shoulder $[\mathrm{P}<0.0001]$ impulses. Moreover, there was a significant interaction between hand and group $[\mathrm{P}=0.0074]$ for shoulder impulse revealing that the young group had greater impulse for the right (D) arm $(0.24 \pm 0.38 \mathrm{Nms})$ as compared to the left (ND) $(0.17 \pm 0.37 \mathrm{Nms})$, while the elderly and children groups showed no significant difference between hands. We found strong hand-group interaction at the shoulder joint parameters emphasizing interlimb differences for the young but not for elderly or children. These results suggested that the lateralization shown in young subjects might not yet be evident at childhood, and that it may be reduced with aging. However this was not so notably evident at the elbow joint indicating that interjoint coordination might be greatly related to synchronization of upper and lower arm segments. In conclusion, joint torques increase significantly with intersegmental coordination in young adults, while remaining comparable in older adults and children.

Figure $6 \mathrm{E}$ and $6 \mathrm{~F}$ show the work (means $\pm \mathrm{SE}$ ) perfomed by the muscles of the arm calculated to each joint. Positive (Figure 6E) and negative (Figure 6F) values of work represent the energy flow during the arm movement (Enoka, 2002).

A significant difference was shown among groups when analyzing the work done $[\mathrm{P}<0.0001]$ to all cases. The young group presented the highest positive (Elbow: $0.47 \pm 0.25 \mathrm{~J}$; Shoulder: $0.48 \pm 0.44 \mathrm{~J}$ ) and negative values (Elbow: $-0.42 \pm 0.21 \mathrm{~J}$; Shoulder: $-0.33 \pm 0.30 \mathrm{~J}$ ), whereas children (Elbow: $0.11 \pm 0.08 \mathrm{~J}$; Shoulder: $0.11 \pm 0.07 \mathrm{~J}$; Elbow: $-0.13 \pm 0.10 \mathrm{~J}$; Shoulder: $-0.06 \pm 0.04 \mathrm{~J})$ and elderly (Elbow: $0.21 \pm 0.18 \mathrm{~J}$; Shoulder: $0.22 \pm 0.16 \mathrm{~J}$; 


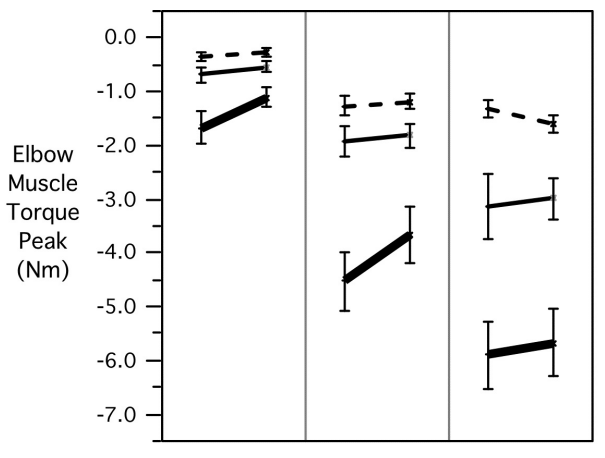

(A)

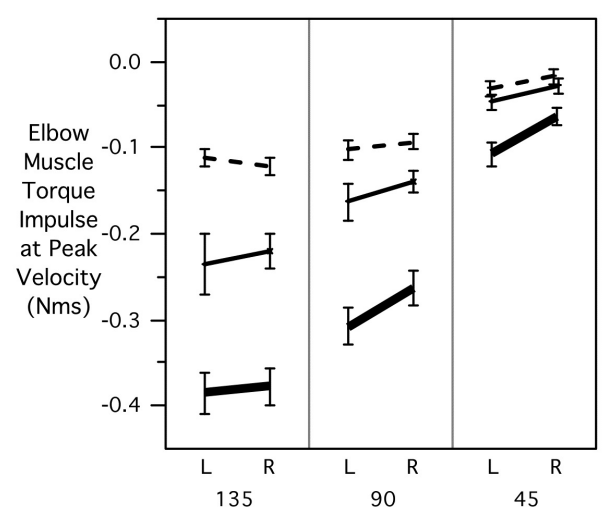

(C)

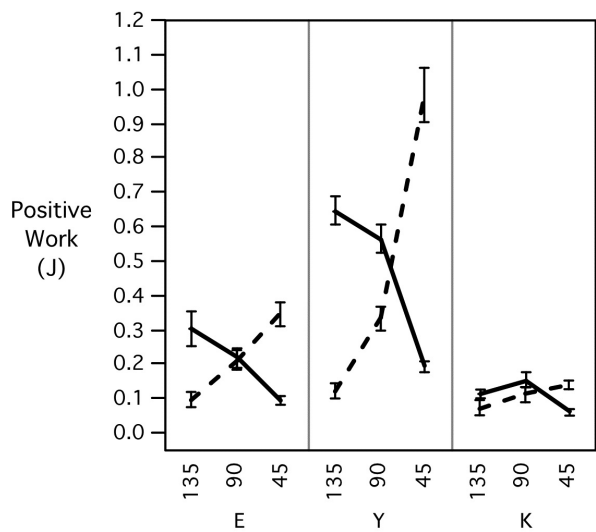

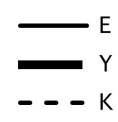

$E$
$Y$
$K$

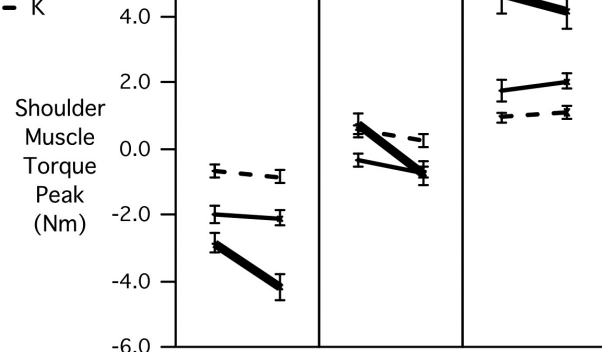

(B)
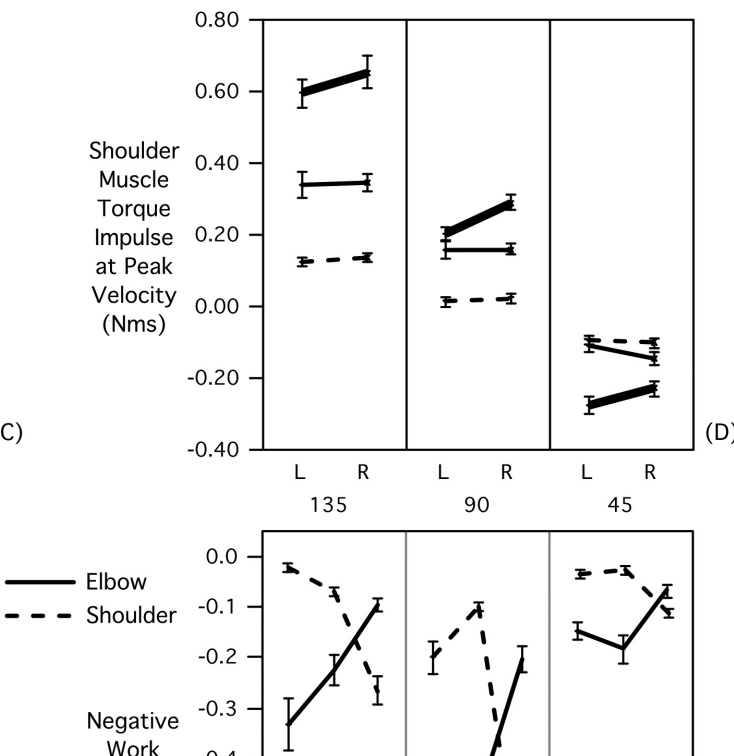

(J)

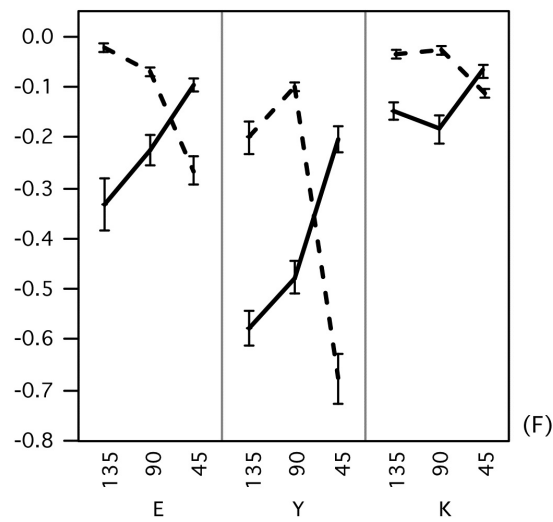

Figure 6. Kinetic comparisons between groups (E: Elder, K: Children, Y: Young), targets (45, 90, and 135) and hands (right (R) and left (L)). (A): Elbow Muscle Torque Peak; (B) Shoulder Muscle Torque Peak; (C): Elbow Muscle Torque Impulse at Peak Velocity; (D) Shoulder Muscle Torque Impulse at Peak Velocity; (E): Positive Work; (F) Negative Work.

Elbow: $-0.22 \pm 0.19 \mathrm{~J}$; Shoulder: $-0.12 \pm 0.13 \mathrm{~J}$ ) groups showed lower values. There was an interaction effect between group and target $[\mathrm{P}<0.0001]$ for all calculated work intervals. These findings suggest that shoulder and elbow work differed across movement directions, which is in agreement with the experiment design; the three targets demanded different movements in terms of directions and hand-paths curvatures, which consistently reflected in the elbow and shoulder joint coordination patterns. The orderly variation of the intersegmental coordination requirements between targets revealed in different responses in the forces transferred from the arm through the upperarm on each group tested, i.e. the young group showed a similar interjoint coordination during the acceleration phase as compared with the deceleration phase. Elder and children groups showed slightly less degree of associantion between elbow and shoulder joints.

\section{Discussion}

The purpose of the current study was to investigate if motor coordination, as defined by particular movement parameters, changes over certain age stages across the 
lifespan. Although there are some studies comparing reaching movements' strategies, little has been said about how this strategy behaves throughout the human life. We examined multidirectional reaching in three different age groups (children (9-12), young (19-24), and elder (65-80) years-old) in order to follow the development of those motor capabilities that might be influenced with age. In our task, subjects were instructed to aim at visually presented targets, starting to move as soon as possible after an audio-visual signal, with a single, fast and uncorrected movement. One of three possible targets appeared at a specific distance and direction from the start circle. Subjects were asked to avoid correcting their trajectories, and they had no visual feedback during movement, so that subjects were not tempted to correct their trajectories while performing the movement.

While the task and some of the analyses used in the present study are similar to our previous paper (Bagesteiro and Silva, 2011) it is important to emphasize that our recent work has extended our investigation by looking at differences in patterns of joint power and work during reaching movements in the horizontal plane. Moreover, consistent patterns of joint power underlie coordinated upper extremity behaviors suggesting that the neuromotor control of these joints may change as a general feature of reaching movements at different age stages. This could have significant consequences for the study of reaching impairments in neurorehabilitation populations.

The young group presented the faster and straighter movements during reaching but, as expected, these characteristics resulted in a lower accuracy. The velocity profile of this group showed narrower peak, which reinforces the idea of a straight movement and fewer direction changes. Children and the elderly seem to start movement with a more curved trajectory (laterally directed), hooking back toward the target at the end of motion. Such strategy can demonstrate an alternative to the lack of speed (not yet fully developed in the case of children and deteriorated in the case of the elder) in performing the movements. Also trying to get a more precise, however less energetic efficient movement.

The three targets showed different joints interactions within groups, but only children had significant differences, which may indicate that this joint ratio is maintained with advancing age but is not fully developed early in life.

Torque profiles were similar in the three groups, however, there was great different on the waveform displayed for each target. Torque and work values were higher for the young group and had similar values for children and the elderly. This could be associated with a greater exchange of energy, which may indicate a decline in performance related to motor tasks with advancing age.

Our findings are in line with previous studies on motor development in children (Ferrel-Chapus et al., 2002; Heineman et al., 2010; Lambert and Bard, 2005; Olivier et al., 2007; Rival et al., 2003; Sveistrup et al., 2008). Additionally, the joint relationships distinctions might be representing an initial acquisition of an adult-like trajectory motion. Previous researches showed indication that in conditions in which speed is emphasized, young and elderly adults can move at similar speeds without sacrificing accuracy; suggesting partially strategic changes employed by older adults to maintain accuracy of performance (Enoka et al., 2003; Francis and Spirduso, 2000; Paizis et al., 2008; Pohl et al., 1996; Semmler et al., 2006). Our results suggest that shoulder and elbow power typically differed largely between young and the other two groups. The young group showed distinctive effect across targets, shoulder and elbow work values were positive or negative (i.e. for each direction, shoulder and elbow either generated or absorbed energy) dependent largely on movement direction. In contrast children had a milder and mixed effect (more similar values across directions), and elderly presented lower values but consistent response. Another important observation is that elbow power tended to linearly correlate to the target direction variation, but this was not as evident for shoulder power.

Previous studies have shown that young subjects present interlimb differences for the kinematics and kinetics patterns (Berret et al., 2011; Graham et al., 2003; Mistry et al., 2013) in the sagittal plane varing with movement direction. Here, we extended these observations on interlimb coordination and kinetics patterns by showing that elder and children groups do not exhibit the asymmetrical pattern between limbs. Moreover, this finding suggests that these specific populations display altered joint kinetics integrating the mechanical effects and generating motor plans that yet minimize the energetic cost of the movement. Also, they could express a more prolonged motor planning that reflects the integration of various objective functions related to kinematics and dynamics. And the fact that they adjust their behaviour to optimise energy expenditure can be used to help understand the breakdown of efficient limb control due to aging.

These findings may indicate that learning reaching movements by acquiring an internal motor model of limb dynamics could be achieved during development, however an analysis involving different tasks and/or a larger number of participants may help to further 
consolidate this finding. One possible suggestion from this data is that some aspects of the coordination and control of a motor task may appear in early life, further develops in adulthood and deteriorates in old age. The fact that elbow and shoulder kinetics were not so different across directions for the children data may suggest the initial development at early age, although this cannot be conclusively determined from the current data.

\section{Acknowledgements}

We thank S. Sousa for assistance with recruiting the participants and with data collection.

\section{References}

Arampatzis A, Knicker A, Metzler V, Brüggemann G. Mechanical power in running: a comparison of different approaches. Journal of Biomechanics. 2000; 33(4):45763. http://dx.doi.org/10.1016/S0021-9290(99)00187-6. PMid:10768394.

Bagesteiro LB, Sainburg RL. Handedness: dominant arm advantages in control of limb dynamics. Journal of Neurophysiology. 2002; 88(5):2408-21. http://dx.doi. org/10.1152/jn.00901.2001. PMid:12424282.

Bagesteiro LB, Silva MV. Joints coordination during arm reaching. In: Associação Brasileira de Engenharia e Ciências Mecânica. COBEM 2011: Proceeedings of the 21st International Congress of Mechanical Engineering; 2011 Oct 24-28; Natal, RN, Brazil. Rio de Janeiro: ABCM; 2011. DVD.

Bagesteiro LB. Aging related responses to conflicting proprioceptive and visual information about initial position during reaching. Revista Brasileira de Engenharia Biomédica. 2013; 29(3):227-41. http://dx.doi.org/10.4322/rbeb.2013.029.

Berret B, Chiovetto E, Nori F, Pozzo T. Evidence for composite cost functions in arm movement planning: an inverse optimal control approach. PLoS Computational Biology. 2011; 7(10):e1002183. http://dx.doi.org/10.1371/ journal.pcbi.1002183. PMid:22022242.

Danion F, Descoins M, Bootsma RJ. Aging affects the predictive control of grip force during object manipulation. Experimental Brain Research. 2007; 180(1):123-37. http:// dx.doi.org/10.1007/s00221-006-0846-3. PMid:17279385.

Enoka RM, Christou EA, Hunter SK, Kornatz KW, Semmler JG, Taylor AM, Tracy BL. Mechanisms that contribute to differences in motor performance between young and old adults. Journal of Electromyography and Kinesiology. 2003; 13(1):1-12. http://dx.doi.org/10.1016/S1050-6411(02)000846. PMid: 12488083.

Enoka RM. Neuromechanics of human movement. 2nd ed. Leeds: Human Kinetics; 2002.

Favilla M. Reaching movements in children: accuracy and reaction time development. Experimental Brain Research. 2006; 169(1):122-5. http://dx.doi.org/10.1007/s00221-0050291-8. PMid:16369792.
Ferrel-Chapus C, Hay L, Olivier I, Bard C, Fleury M. Visuomanual coordination in childhood: adaptation to visual distortion. Experimental Brain Research. 2002; 144(4):506-17. http://dx.doi.org/10.1007/s00221-002-10642. PMid:12037635.

Francis KL, Spirduso WW. Age differences in the expression of manual asymmetry. Experimental Aging Research. 2000; 26(2):169-80. http://dx.doi.org/10.1080/036107300243632. PMid:10755223.

Gooderham SE, Bryden PJ. Does your dominant hand become less dominant with time? The effects of aging and task complexity on hand selection. Developmental Psychobiology. 2014; 56(3):537-46. http://dx.doi.org/10.1002/ dev.21123. PMID: 23765799.

Graham KM, Moore KD, Cabel DW, Gribble PL, Cisek P, Scott SH. Kinematics and kinetics of multi-joint reaching in non- human primates. Journal of Neurophysiology. 2003; 89(5):2667-77. http://dx.doi.org/10.1152/jn.00742.2002. PMid:12612006.

Heineman KR, Middelburg KJ, Hadders-Algra M. Development of adaptive motor behaviour in typically developing infants. Acta Paediatrica. 2010; 99(4):61824. http://dx.doi.org/10.1111/j.1651-2227.2009.01652.x. PMid:20050831.

Heuninckx S, Debaere F, Wenderoth N, Verschueren S, Swinnen SP. Ipsilateral coordination deficits and central processing requirements associated with coordination as a function of aging. The Journals of Gerontology. Series B, Psychological Sciences and Social Sciences. 2004; 59(5):225-32. http://dx.doi.org/10.1093/geronb/59.5.P225. PMid:15358795.

Holtrop JL, Loucks TM, Sosnoff JJ, Sutton BP. Investigating age-related changes in fine motor control across different effectors and the impact of white matter integrity. NeuroImage. 2014; 96:81-7. http://dx.doi.org/10.1016/j. neuroimage.2014.03.045. PMid:24657352.

Lambert J, Bard C. Acquisition of visuomanual skills and improvement of information processing capacities in 6 to 10 year old children performing a $2 \mathrm{D}$ pointing task. Neuroscience Letters. 2005; 377(1):1-6. http://dx.doi. org/10.1016/j.neulet.2004.11.058. PMid:15722176.

Lee G, Fradet L, Ketcham CJ, Dounskaia N. Efficient control of arm movements in advanced age. Experimental Brain Research. 2007; 177(1):78-94. http://dx.doi.org/10.1007/ s00221-006-0648-7. PMid:16944112.

Linortner P, Jehna M, Johansen-Berg H, Matthews PM, Schmidt R, Fazekas F, Enzinger C. Aging associated changes in the motor control of ankle movements in the brain. Neurobiology of Aging. 2014; 35(10):2222-9. http://dx.doi. org/10.1016/j.neurobiolaging.2014.04.013. PMid:24836898.

Mistry M, Theodorou E, Schaal S, Kawato M. Optimal control of reaching includes kinematic constraints. Journal of Neurophysiology. 2013; 110(1):1-11. http://dx.doi. org/10.1152/jn.00794.2011. PMid:23554437.

Mutha PK, Haaland KY, Sainburg RL. Rethinking motor lateralization: Specialized but complementary mechanisms for motor control of each arm. PLoS One. 2013; 8(3):e58582. http:// dx.doi.org/10.1371/journal.pone.0058582. PMid:23472210. 
Oldfield RC. The assessment and analysis of handedness: the Edinburgh Inventory. Neuropsychologia. 1971; 9(1):97113. http://dx.doi.org/10.1016/0028-3932(71)90067-4. PMid:5146491.

Olivier I, Hay L, Bard C, Fleury M. Age-related differences in the reaching and grasping coordination in children: unimanual and bimanual tasks. Experimental Brain Research. 2007; 179(1):17-27. http://dx.doi.org/10.1007/s00221-0060762-6. PMid:17091289.

Paizis C, Papaxanthis C, Berret B, Pozzo T. Reaching beyond arm length in normal aging: adaptation of hand trajectory and dynamic equilibrium. Behavioral Neuroscience. 2008; 122(6):1361-70. http://dx.doi.org/10.1037/a0013280. PMid:19045955.

Pohl PS, Winstein CJ, Fisher BE. The locus of age-related movement slowing: sensory processing in continuous goal-directed aiming. The Journals of Gerontology. Series B, Psychological Sciences and Social Sciences. 1996; 51(2):94-102. http://dx.doi.org/10.1093/geronb/51B.2.P94. PMid:8785692.

Przybyla A, Haaland KY, Bagesteiro LB, Sainburg RL. Motor asymmetry reduction in older adults. Neuroscience Letters. 2011; 489(489):99-104. http://dx.doi.org/10.1016/j. neulet.2010.11.074. PMid:21144883.

Rival C, Olivier I, Ceyte H. Effects of temporal and/or spatial instructions on the speed-accuracy trade-off of pointing movements in children. Neuroscience Letters. 2003; 336(1):65-9. http://dx.doi.org/10.1016/S03043940(02)01246-6. PMid:12493603.

Sainburg RL, Kalakanis D. Differences in control of limb dynamics during dominant and nondominant arm reaching. Journal of Neurophysiology. 2000; 83(5):266175. PMid:10805666.

Sainburg RL, Schaefer SY. Interlimb differences in control of movement extent. Journal of Neurophysiology. 2004; 92(3):1374-83. http://dx.doi.org/10.1152/jn.00181.2004. PMid:15115793.

Sainburg RL. Evidence for a dynamic-dominance hypothesis of handedness. Experimental Brain Research. 2002; 142(2):241-58. http://dx.doi.org/10.1007/s00221-001-09138. PMid:11807578.

Schepens B, Willems PA, Cavagna GA, Heglund NC. Mechanical power and efficiency in running children. European Journal of Phycology. 2001; 442(1):107-16. PMid:11374057.
Schneiberg S, Sveistrup H, McFadyen B, McKinley P, Levin MF. The development of coordination for reach-to-grasp movements in children. Experimental Brain Research. 2002; 146(2):142-54. http://dx.doi.org/10.1007/s00221002-1156-z. PMid:12195516.

Seidler RD, Bernard JA, Burutolu TB, Fling BW, Gordon MT, Gwin JT, Kwak Y, Lipps DB. Motor control and aging: Links to age-related brain structural, functional, and biochemical effects. Neuroscience and Biobehavioral Reviews. 2010; 34(5):721-33. http://dx.doi.org/10.1016/j. neubiorev.2009.10.005. PMid:19850077.

Semmler JG, Kornatz KW, Meyer FG, Enoka RM. Diminished task-related adjustments of common inputs to hand muscle motor neurons in older adults. Experimental Brain Research. 2006; 172(4):507-18. http://dx.doi.org/10.1007/s00221006-0367-0. PMid:16489433.

Shadmehr R, Moussavi ZM. Spatial generalization from learning dynamics of reaching movements. The Journal of Neuroscience. 2000; 20(20):7807-15. PMid:11027245.

Sveistrup H, Schneiberg S, McKinley PA, McFadyen BJ, Levin MF. Head, arm and trunk coordination during reaching in children. Experimental Brain Research. 2008; 188(2):237-47. http://dx.doi.org/10.1007/s00221-008-13571. PMid: 18392615.

Tutkuviene J, Schiefenhövel W. Laterality of handgrip strength: age- and physical training-related changes in Lithuanian schoolchildren and conscripts. Annals of the New York Academy of Sciences. 2013; 1288(1):124-34. http://dx.doi.org/10.1111/nyas.12126. PMid:23701486.

Wilson PH, Hyde C. The development of rapid online control inchildren aged 6-12 years: Reaching performance. Human Movement Science. 2013; 32:1138-50.

Winter DA. Biomechanics and motor control of human movement. New York: John Wiley and Sons; 2004.

Winter DA. Moments of force and mechanical power in jogging. Journal of Biomechanics. 1983; 16(1):91-7. http:// dx.doi.org/10.1016/0021-9290(83)90050-7. PMid:6833314.

Yan JH. Effects of aging on linear and curvilinear aiming arm movements. Experimental Aging Research. 2000; 26(4):393407. http://dx.doi.org/10.1080/036107300750015778. PMid:11091944.

Zelik KE, Kuo AD. Mechanical work as an indirect measure of subjective costs influencing human movement. PLoS One. 2012; 7(2):e31143. http://dx.doi.org/10.1371/journal. pone.0031143. PMid:22383998.

\footnotetext{
Authors

Marcus Vinicius da Silva ${ }^{1}$, Leia Bernardi Bagesteiro ${ }^{2 *}$

${ }^{1}$ Centro de Engenharia, Modelagem e Ciências Sociais Aplicadas - CECS, Universidade Federal do ABC - UFABC, Santo André, SP, Brazil.

${ }^{2}$ Laboratório de Instrumentação Eletro-Eletrônica - IEE, Departamento de Engenharia Elétrica - DELET, Escola de Engenharia, Universidade Federal do Rio Grande do Sul - UFRGS, Av. Osvaldo Aranha, 103, Sala 206, CEP 90035-190, Porto Alegre, RS, Brazil.
} 